\title{
Bat Rabies
}

\author{
BY ROBERT D. COURTER, D.V.M.
}

$\mathrm{T}$ THE RECOGNITION of rabies infection in insectivorous bats is an interesting and significant discovery which may have far-reaching implications as a new public health problem in the United States.

The existence of rabies infection in bats of the United States was unknown until June 1953, when it was diagnosed by the Tampa regional laboratory of the Florida State Board of Health (1). The first bat found to be infected was a Florida yellow bat (Dasypterus floridanuas), which had been killed while attacking a 7-year-old boy near Tampa. Diagnosis was established by the presence of Negri bodies on microscopic examination in routine diagnostic procedures by W. R. Hoffert, senior bacteriologist in the Tampa regional laboratory. Rabies infection was confirmed by inoculation of mice with the bat brain in the Jacksonville laboratory of the Florida Board of Health. The virus isolated was sent to the Virus and Rickettsia Laboratory of the Public Health

Robert D. Courter is assistant chief of the Veterinary Public Health Section, Communicable Disease Center, Public Health Service, Atlanta. He served as a public health veterinarian with the American Mission for Aid to Greece for 3 years and with the Military Government in Europe for 2 years. While in Greece, Dr. Courter was awarded an honorary degree from the Veterinary College of the University of Thessaloniki (Salonica). He received his doctorate in veterinary medicine from lowa State College in 1936.

Vol. 69, No. 1, January 1954
Service Communicable Disease Center, Atlanta, where it was confirmed as rabies virus by neutralization and by complement fixation tests.

Subsequently, Dr. James E. Scatterday and other members of the Florida Board of Health found rabies virus in the brains of five yellow bats (Dasypterus floridanus) and one Seminole bat (Lasiurus seminola) which were apparently normal and had been killed in flight while feeding. Both species are insectivorous and indigenous to the southeastern United States.

In September 1953, Dr. Ernest Witte, Pennsylvania State Department of Health, reported that rabies infection had been recognized in a bat which made an unprovoked attack upon a woman near Carlisle, Pa. The brain was examined in the Pennsylvania Bureau of Animal Industry Laboratory where positive evidence of rabies was found. This diagnosis was confirmed by the inoculation of rabbits. The woman was given Pasteur treatment and to date remains healthy. Unfortunately, the bat carcass was destroyed before the genus or species could be determined; however, there was general agreement among the people who saw the bat that it was insectivorous.

These findings have revealed a probable reservoir and source of infection in a new group of wildlife with feeding and living habits entirely different from those of animals heretofore known to harbor rabies virus in this country. As an aid in understanding this new problem, it seems desirable to present a review of bat rabies in Latin America, where the disease has existed for half a century. The designation "bat rabies" is used in the absence of better 
terminology for that form of rabies transmitted by bats and usually occurring in humans and in livestock as paralyses; also occurring in several forms among hemophagous and frugivorous bats of Latin America.

\section{History and Distribution}

The existence of rabies among bats was first recognized in Brazil during investigations of a paralytic disease among cattle, erroneously called "mal de caderas de bovinos," which had appeared as an epizootic in 1908 along a narrow strip between the mountains and the sea. Pawan (2) cited Carini's discovery in 1911 of Negri bodies in the brains of cattle dying of this paralytic disease, which was epizootic in the state of Santa Catarina. At the beginning of the outbreak, the inhabitants of Santa Catarina noticed that, although bats are normally nocturnal animals, many were seen flying about and biting animals during the daytime. Carini emphasized that bovines bitten by such bats invariably developed "mal de caderas," and bats were suspected as being the carriers of this disease. Bats could not be obtained for examination, and, when the disease was diagnosed as rabies, dogs were suspected of being responsible for its spread.

Sporadic cases of rabies had occurred among dogs in the infected area simultaneously with the cattle disease with the result that a dog quarantine was strictly enforced, and almost , 000 dogs were killed in 6 months in 1912. The paralytic disease of cattle continued unabated. Observations revealed that the disease was usually found near forests. It was also noted that rivers, which were impassable to dogs, offered no barrier to the spread of the disease in cattle.

\section{Other Latin American Epizootics}

Pawan (2) records that while Haupt and Rehaag were studying "mal de caderas" in the town of Blumenau, in southern Brazil, from 1914 to 1921, they were impressed by the unusual behavior of bats: flying in the daytime, fighting among themselves, and attacking animals. They concluded that such abnormal aggression and fits among the bats must be signs of disease. The inhabitants of the Blumenau area had observed that the animals bit- ten by bats during the daytime invariably died, and they were convinced that vampire bats, because they were known normally to feed on cattle, were responsible for the spread of "mal de caderas" in cattle.

In 1916, Rehaag isolated rabies virus from a fruit-eating bat (Phyllostoma supercilliatum) caught while biting cattle during the daytime. He found Negri bodies in rabbits and guinea pigs which he infected with this rabies virus. During the studies on the epizootic, it was noted also that destruction of dogs in the area had no limiting influence on the disease among cattle.

Pawan (2) reported that after these discoveries were made Haupt and Rehaag concluded that the repeated epizootics of paralytic disease in the livestock of southern Brazil were caused by rabies virus which was being transmitted by bats.

\section{In Trinidad}

The disease continued to spread on the South American continent and, in 1925, appeared among cattle in Mucurapo and Saint Anns in northern Trinidad, where it was again erroneously diagnosed, this time as botulism (3). During the next few years, other investigators in Brazil, Paraguay, and Argentina concluded that rabies virus caused the paralytic epizootics among the livestock of South America (4).

Until 1929 all rabies suspected of being transmitted by bats had occurred only in animals, but suddenly there appeared in the village of Siparia in southern Trinidad an epidemic of ascending paralytic myelitis in humans which Hurst and Pawan (4) found to be caused by the virus of rabies. During this epidemic, authentic accounts were given of bats flying from fruit trees and attacking humans and animals. The probability is that these bats were fruiteaters and were rabid. The paralysis associated with the disease in humans and in cattle, together with the history of bat bites in both, led to the suspicion that blood-lapping bats were transmitting the disease, despite the evidence that vampire bats had been feeding on humans in Trinidad for some 60 years. Pawan $(\mathscr{D})$ in 1936 reported results of investigations which showed that vampire bats do transmit rabies in both humans and livestock. 
Pawan (2) found circumstantial evidence that bat rabies may have occurred in Trinidad prior to the 1925 outbreak:

Records of the Trinidad colony indicated that in the distant past attempts to establish stock farms in the areas near the villages of San Francique and Siparia had failed because of the ravages of bats.

While dissecting vampire bats to determine the nature of their stomach contents, in 1889 , a chemist developed a fatal paralysis which was certified as "acute ascending spinal paralysis."

In the continued absence of recognized rabies, in 1919, a peasant girl and woman were bitten on the lower extremities by a "strange mad cat." Six weeks later, each developed a severe burning sensation at the site of the wound, and paralysis followed. Death occurred 3 days after the onset of symptoms.

\section{In Mexico}

Bat rabies was recognized in Mexico during studies of a highly fatal paralytic disease of livestock, which had been prevalent for nearly half a century in the west coastal states of Mexico (5). This disease was called "derriengue," or "el tronchado," and during the last decade it appeared to be the major livestock problem in parts of Mexico. There were at least 10,000 cases of derriengue in cattle yearly between 1939 and 1943. Johnson (5) reported than Ten Broeck, and later Johnson himself, isolated rabies virus from the salivary glands and brain of a paralyzed cow and from the salivary glands and brains of vampire bats (Desmodus rotuondus murinus Wagner) in the area of the disease. Dogs did not appear to be associated with the transmission of derriengue. MálagaAlba (6), in 1953, reported bat rabies from several other parts of the country. Positive laboratory diagnosis has been made of bat rabies in three states, Sonora, Chihuahua, and Tamaulipas, which border on the United States. The disease now occurs in most of the states of Mexico.

\section{In Honduras}

Schroeder ( $y$ ) diagnosed vampire bat rabies as "derriengue" while investigating cattle losses at La Ceiba, Honduras, in 1950. He confirmed rabies by mouse inoculation in 6 of the 7 cattle studied. Negri bodies were found in the brain of the seventh animal, but mice inoculated with this brain material failed to yield virus.

\section{In Venezuela}

Briceno Rossi (8), in 1953, reports the existence of paralytic rabies in cattle in various stock-raising areas of Venezuela where the disease occasionally takes epizootic form and is transmitted by vampire bats. The bovine-type virus has been isolated from dogs, but dogs have not been implicated in transmitting the disease. There is no evidence of the disease in humans in Venezuela.

\section{The Virus Isolated from Bats}

The rabies virus isolated from bats has been shown by pathological findings, animal inoculation, complement fixation, cross-neutralization, and protection tests to be closely related to classical strains of rabies virus $(2,5)$. It has been likened to the virus of the "oulo-fato" form of rabies found in indigenous dogs of French West Africa in that both viruses usually produce the paralytic form of rabies $(9)$.

In studies of the clinical course of rabies in bats, Pawan (10) used a human strain of virus which had produced the paralytic form of rabies, but upon subcutaneous inoculation into vampire bats it produced both the furious and the paralytic forms of the disease. Pawan demonstrated that the Trinidad virus travels readily to the salivary glands in bats, the saliva sometimes becoming highly virulent as early as 7 days following subcutaneous inoculation, while the bat itself may manifest no sign of disease.

The species specificity of the virus maintained in bats has been altered as is true of rabies virus subjected to extended propagation in the experimental and laboratory animals (5). The slight differences which appeared in Johnson's neutralization and protection tests may be explained somewhat by the low infectivity index of freshly isolated rabies virus and the high infectivity of brain tissue infected with fixed virus. Rabbits immunized by Hurst and Pawan (3) with killed fixed virus were protected against subsequent injection of Trinidad 
vampire bat virus, but, on the other hand, the Trinidad virus did not confer much resistance against fixed virus.

In addition to the animals mentioned previously, bat rabies virus has been experimentally transmitted to guinea pigs, cats, rats, mice, dogs, hens, and buzzards. After intracerebral injection, dogs developed paralysis, in the posterior limbs first, and some of them showed a tendency to bite (11). Hurst and Pawan (3) report the paralytic form of rabies in rabbits following intracerebral injection, although Van Rooyen and Rhodes (11) record that Remlinger and Bailly noted a fairly long stage of motor excitement before the onset of paralysis. Van Rooyen and Rhodes reported that Andrews had shown the guinea pig to be more susceptible to the Trinidad virus than to ordinary rabies virus.

Hurst and Pawan (3) made extensive histological studies of the brains and spinal cords of monkeys and rabbits which were experimentally infected in Trinidad. They observed that infection of monkeys with the Trinidad virus may give rise to very scanty cellular lesions, detectable only on very careful examination, or to marked inflammatory and parenchymatous changes scattered diffusely over the central nervous system. There also seemed to be a third group showing lesions of intermediate severity between the very scanty changes in the first group and the intense changes in the second. In the cortex of all groups, small compact microglial foci occurred, formed in many cases around a degenerate nerve cell. The cerebrum showed meningeal infiltration, perivascular cuffing, and well-developed microglial foci. When definite lesions were found in the brains, marked changes were seen also in the spinal, gasserian, and sympathetic ganglia. Many nerve cells were degenerate, or actually necrotic, and were often replaced by capsular cells. Negri bodies were found regularly in the experimental disease of monkeys.

\section{The Nature of the Disease}

Bat rabies occurs in nature in humans, in herbivorous animals, and in hemophagous and frugivorous bats. Rabid dogs have been seen frequently in areas where bat rabies was epi- zootic, but the dogs could not be connected with these epizootics. Natural infection has not been reported in dogs except in Venezuela where bat rabies virus has been isolated from dogs $(8)$.

The average incubation period in $D$. rotundaus is 25 days, but one bat showed probable symptoms on the third day following inoculation and then returned to normal until the seventh day when definite rabies symptoms appeared (10). The longest known incubation period was in a vampire bat which was infected in nature prior to capture and which remained infective without symptoms for $51 / 2$ months. At the end of this period, its brain was removed and was injected subcutaneously into guinea pigs, producing rabies in them. Pawan (10) reports that in 1934 Lima showed that Desmodus which had been infected experimentally with bovine virus can remain infective without evidence of disease for 1 to $51 / 2$ months. The average length of life of the frugivorous bats (Artibeus) following inoculation with rabies virus was 130 days.

Six forms of rabies in Desmodus bats were observed and classified by Pawan (10) as follows:

The typical classical furious rabies in which fury is a prominent and predominating feature, followed by paralysis and death.

The typical paralytic form of rabies, in which no state of fury or excitement can be observed, but in which paralysis runs into death.

A furious type of rabies, in which the stage of fury is followed by recovery.

A furious form in which fury runs on directly to death with no intervening paralysis.

A form in which the bat is well but dies suddenly and unexpectedly without any previous evidence of illness.

A subclinical or latent form of infection, in which the bat continues to live without any apparent departure from normal.

\section{The Classical Form}

In the classical form of bat rabies, there is the usual incubation period, a prodromal or invasive stage, then a stage of excitement, and 
lastly paralysis, ending in death. The prodromal stage of from 12 to 24 hours' duration may be seen when the bat is restless, easily irritated, and there are muscular tremors, or the bat may be apathetic and off feed. This stage is rapidly followed by excitement, fury, and various signs of deranged behavior. Paralysis may first appear as a paresis of one limb or may develop suddenly as a "stony" paralysis. It most commonly involves the wing muscles and those controlling the bladder, producing incontinence of urine. The duration of paralysis is from 1 to 5 days, and in its main features it suggests the disease as seen in other animals and humans.

The predominant symptom observed in frugivorous bats is deranged behavior, during which time they may bite other animals. As with the blood-lapping bats, fruit-eating bats may be refractory to clinical infection with rabies virus; however, the saliva of infected bats may contain the virus when they manifest no evidence of disease (12).

\section{The Paralytic Form}

The paralytic form of rabies is usually seen in cattle which have been infected by bats. It is characterized by an initial period of restlessness and excitement which is soon followed by a sudden onset of paralysis of the rear quarters. The common name for this disease in Mexico, derriengue, is derived from the Spanish word meaning a break in, or an injury to, the spine (5). Affected animals ordinarily live for several days; during this time paralysis extends to the forequarters and neck. Salivation is noted early and results from a difficulty in swallowing.

Emaciation develops rapidly, and the disease seems to be uniformly fatal. The sudden onset of posterior paralysis and the rapid extensive emaciation seem to be aimost pathognomonic. The loss of cattle during an epizootic may be high. Johnson (5) reported that when derriengue appears in epizootic proportions it may kill 20 to 50 percent of the cattle in the immediate area, and Schroeder ( $(7)$ reported that single ranches in Honduras lost as much as 40 percent of their cattle over a 4-month period during an epizootic.

Symptoms in humans appear suddenly, usually 3 to 4 weeks following the bite of an in- fected bat. The first complaint is usually a burning or tingling sensation in the bitten limb, and there may be paresis in the affected limb at the onset of the disease (11). The patient is febrile and often has a headache. Following these prodromal symptoms, which may last from 1 to 4 days, muscular weakness progresses to complete paralysis of the affected limb. The trunk muscles and arms are soon involved, terminating in a fatal paralysis usually about the seventh day after the onset of symptoms.

\section{Epizootiology}

The incidence of bat rabies is cyclical, and the disease in both humans and animals occurs in epidemic form. The outbreaks, usually confined to relatively small areas, are frequently limited to valleys and arroyos which are inhabited by vampire bats. In Trinidad, however, the animal disease occurred in large numbers over the entire island at one time or another between 1925 and 1935, while the human disease remained confined to a few small areas (13). The epizootics usually end in from 1 to 2 months, followed by the appearance of sporadic cuses for several months in the area. Subsequently, the disease may entirely disappear for 1 or 2 years before another outbreak.

\section{Seasonal Occurrence}

Seasonal distribution is quite constant, the incidence peaking in January and February, with most of the cases in 1 year occurring between October and April (5). This seasonal occurrence may be traced to the breeding habits of the bats. The first sign of an approaching epizootic is the existence of the disease in vampire bats (Desmodus), as evidenced by an increase in the frequency with which they bite humans and animals. In epidemics, the animal disease has invariably preceded the appearance of the disease in humans.

\section{The Nonhemophagous Bats}

The nonhemophagous bats have not been considered as transmitters of rabies to other animals and humans, although the disease has been recognized in four genera which were infected in nature. Pawan (2) reports that Rehaag first recognized rabies in the Phyllostoma supercil- 
liatum, a fruit-eating bat. Pawan (2) later recognized the infection in the Artibeus, the Hemiderma, and the rare Dicliduras, all three of which he classified as frugivorous and insectivorous. Johnson (5) has listed the Hemiderma as insectivorous. Colin Campbell Sanborn, curator of the Chicago Natural History Museum, states that the Phyllostoma, Artibeus, and Hemiderma (in current terminology, Carollia) are fruit-eating and are not insectivorous.

Although the nonhemophagous bats have not been considered of major importance in the transmission of bat rabies to humans and animals, these bats have been found attacking animals when they were deranged with rabies, and they may transmit the disease. The frequency with which rabies infection has been found in the nonhemophagous bats during epizootics among the blood-lapping bats and livestock leads to a strong suspicion that they play a very important role in either harboring rabies virus or in transmitting it to the hemophagous bats and perhaps to animals.

\section{Desmodus, the Transmitter}

The hemophagous vampire bat, Desmodus, is the proved transmitter of bat rabies to humans and animals. The vampire bats ( $D$. rotumdus murinus Wagner and Desmodus rufus Weid) are a constant threat as a source of infection because of their normal feeding and living habits. They live in large colonies within easy flying range-usually about 1 mile-of the animals upon which they feed. Blood is obtained from the host through a typical crater-like wound, upon which several bats may feed at the same time, and they frequently retuirn to the same host on successive nights. After feeding, they rest in various hiding places, which may be frequented by nonhemophagous bats, before returning to their usual roosting places.

The known habitat of the vampire bat is from the 30th parallel south latitude to the 28th parallel north latitude, or, from just north of Uruguay in South America to just north of Cuidad Victoria, Tamaulipas, Mexico, in North America. The many reports of bat rabies in widely separated parts of this area indicate that this disease presents a problem in all areas inhabited by the vampire bats.

\section{Control of the Disease}

Control activities should be directed toward the destruction of vampire bats or any other bat known to harbor and transmit rabies virus. Bat populations near villages or other thickly popu. lated areas can be successfully limited by destruction of the colonies.

Limiting the bat populations in sparsely settled regions where livestock range over large areas is more difficult and, in some cases, almost impossible. In these areas, livestock may be protected, as is done in Mexico, by moving them 15 to 20 miles from an area in which bat rabies is occurring.

Protection may be accomplished through bat-proofing homes and animal shelters. In some areas, bright lights have been used to keep vampires away.

While the destruction of the blood-feeding vampire bat remains the main objective in antirabies bat campaigns, it should not be forgotten that the nonhemophagous bats may bite animals and transmit rabies. Measures for reducing their numbers should be included in any control campaign.

\section{Immunization}

In areas where bat populations cannot be eliminated, susceptible animals can be protected by immunization with rabies vaccine. Vaccination of livestock for the prevention of derriengue was practiced in Mexico before the vampire bat was implicated as the transmitting agent (5). An extensive immunization program was begun in 1936, using a vaccine consisting of a 20-percent suspension of infected sheep brain in saline containing 0.5 percent Formalin. In his 1951 annual report on the Mexico-United States rabies agreement, Dr. Aurelio Málaga-Alba, WHO rabies consultant, reported that he successfully used avianized vaccine prepared from the Flury strain, in 1951, to produce a high immunity against challenge with the derriengue virus. Subsequently, he vaccinated 3,500 cattle with this avianized vaccine with no known failures, although other animals in the area which had been vaccinated with brain tissue vaccine contracted the disease. Schroeder ( 7$)$ reported equally good protection in Honduras with the avianized Flury 
strain vaccine. Approximately 5,000 cattle were vaccinated intramuscularly in an area where bat rabies was epizootic, and none of them came down with rabies, whereas the incidence of rabies continued high in unvaccinated cattle.

\section{Discussion}

Bat rabies has been occurring in Latin America for half a century or longer and has been recognized as a public health and economic problem of considerable importance in that area for at least two decades. The very nature of the living and feeding habits of the bats which transmit this disease presents a most difficult problem of control. In the United States, there has been little concern that bat rabies would be encountered in this country because the known carrier was confined by climatic requirements to warm areas some distance from the southern border. Since Johnson's original report (5), Malaga (6) has found the disease in Sonora, Chihuahua, and Tamaulipas, three states in Mexico which border on the United States. Whether infected vampire bats are moving northward or whether the bats have been present in the border areas for a number of years is difficult to determine.

A 1952 survey in southern California by the Pan American Sanitary Bureau resulted in no positive proof of vampire bats in that area, but it did reveal circumstantial evidence of their presence. The evidence indicates that an exhaustive survey in the area is warranted:

A bat, perhaps a vampire, was observed by a member of the United States Fish and Wildlife Service. It was seen at close range, walking on all fours in the quadrupedal gait typical of vampire bats, and was identified as a vampire from a picture of a $D$. rotuondus.

Stabled horses with bleeding ears were found in the morning, on other occasions, and bat bites were suspected when no other definite cause could be found for the bleeding.

Ranchers in northern Baja California, Mexico, were complaining that bats had been damaging the teats of nursing sows. (It is known that when bats do attack hogs they prefer the flanks or mammae.)
There were reports of two cases of paralytic rabies in cattle in San Diego County, Calif., yet there was no history of these cattle having been bitten by other animals or of rabies in dogs or coyotes in the immediate area.

Paralytic cases of a disease resembling rabies, followed by recuperation, have been reported in the area. A case of posterior paralysis was reported in an animal that was ill for several days before it was slaughtered, but the brain was not examined.

The circumstantial evidence of bat rabies in southern California, the spread of derriengue in Mexico, and the recent recognition of rabies infection among insectivorous bats in Florida and Pennsylvania may lead to a change in the concept of a bat rabies problem in the United States.

\section{The Problem in the United States}

Because the habitat of the vampire bat is limited by temperature requirements to a warm climate, it is not likely that this bat will present a problem in the United States except, perhaps, in the southern fringe of the country. Insectivorous species which are common in the southern United States are also known to inhabit areas in Mexico from which rampire bats have been reported. It seems likely that rabies could be passed and maintained among these different species. It is also possible that bats could be infected by rabid sarnivores and, in turn, could pass the infection on to other bats and animals. The apparently healthy bats in Florida which have been found to be infected with rabies indicate that the disease may be latent and asymptomatic in the insectivorous bat, as has been observed in the hemophagous and frugivorous species of Latin America.

\section{$A$ Limited Strady}

The behavior of the virus in experimentally infected insectivorous bats was shown in a limited experiment on 41 bats by Reagan and Brueckner (14). They successfully inoculated two species of insectivorous bats with rabies virus isolated in mice from the brain of a dog. Five passages were made in the big brown bat (Eptesicus fuscus), and the brains from each passage were injected into mice. In the first 
three passages, 85 percent of the inoculated bats developed the disease in 4 to 9 days, and Negri bodies were numerous in all bat brains and in all but one of the mice brains. In the fourth and fifth passages, 60 percent of the inoculated bats developed the disease in from 4 to 14 days, and only occasional Negri bodies were noted in each brain of the diseased bats. Negri bodies were found in only one-half of the mice brains from these two passages.

Conclusions can hardly be drawn from this limited study, but it may indicate that the virus is altered as it passes through bats. The infectivity seems to lessen, the incubation period lengthens, and the incidence of Negri bodies diminishes. This is in contrast to the usual host-parasite relationship of the rabies virus, in which the host becomes more susceptible, and the incubation period becomes shorter with increasing passage until the virus becomes fixed.

The present information on rabies in bats of the United States is insufficient to permit more than a conjecture as to the public health problems which now exist or which may develop in this country. Much additional study is needed on the prevalence of rabies infection in bats, the pathogenesis of the disease and the nature of the virus in them, and the transmission of rabies by insectivorous bats to other animals.

\section{REFERENCES}

(1) Provisional information on selected notifiable diseases in the United States for week ended August 1, 1953. Morbidity and Mortality Weekly Rep. 2: 1-6 (Aug. 7, 1953).
(2) Pawan, J. L.: The transmission of paralytic rabies in Trinidad by the vampire bat. Ann. Trop. Med. 30: 101-130 (1936).

(\$) Hurst, E. W.; and Pawan, J. L.: A further account of the Trinidad outbreak of acute rabic myelitis: History of the experimental disease. J. Path. \& Bact. 35: 301-303 (1936).

(4) Hurst, E. W., and Pawan, J. L.: An outbreak of rabies in Trinidad. Lancet 2: 622-628 (1931).

(5) Johnson, H. N.: Derriengue: Vampire bat rabies in Mexico. Am. J. Hyg. 47: 189-204 (1948).

(6) Malaga-Alba, A.: Border state vampires. Texas Health Bull. 6: 4-7 (June 1953).

(7) Schroeder, C. R.: Rabies in central and southern America. In Proc., Annual meeting, American Veterinary Medical Association, 1952. Chicago, The Association, 1952, pp. 411-412.

(8) Briceno Rossi, A. L.: Experience gained during an epizootic of canine rabies in Caracas, Venezuela. Report at meeting of the World Health Organization Expert Committee on Rabies. Rome, 1953.

(9) Nicolau, S., Mathis, C., and Constantinesco, V.: La rage autochtone (maladie de chien fou) en Afrique occidental francaise (Etude critique et expérimentale). Ann. Inst. Pasteur 50: 778-839 (1933).

(10) Pawan, J. L.: Rabies in the vampire bat of Trinidad with special reference to the clinical course and latency of infection. Ann. Trop. Med. 30: 401-422 (1936).

(11) Van Rooyen, C. E., and Rhodes, A. J.: Virus diseases of man. Ed. 2. New York, Thomas Nelson and Sons, 1948, p. 792.

(12) Pawan, J. I.: Fruit eating bats and paralytic rabies. Ann. Trop. Med. 42: 173-177 (1948).

(13) de Verteuil, E., and Urich, F. W.: The study and control of paralytic rabies transmitted by bats in Trinidad, British West Indies. Tr. Roy. Soc. Trop. Med. \& Hyg. 29: 317-354 (1935-36).

(14) Reagan, R. L., and Brueckner, A. L.: Transmission of a strain of rabies virus to the large brown bat (Eptesicus fuscus) and to the cave bat (Myotis lucifugus). Cornell Vet. 41: 295298 (1951).

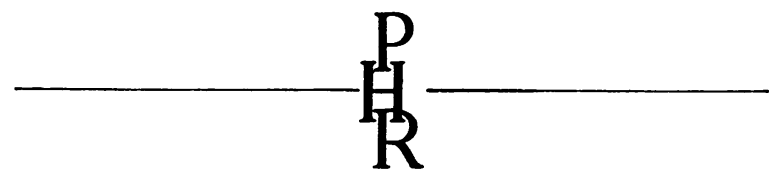

